\title{
Measurement and Empirical Analysis of Public Governance Index Based on Factor Analysis and Shapley Choquet Integral
}

\author{
Hao Cheng ${ }^{\text {a) }}$, Zhiming $\left.\mathrm{Hu}^{*}, \mathrm{~b}\right)$, Lei $\mathrm{Yu}^{\mathrm{c})}$
}

School of Management, Qingdao University of Technology, Qingdao 266520, China

a)chenghao@qtech.edu.cn, b)huzhiming1992@126.com, c)1301588562@qq.com

Keywords: Measurement, Empirical analysis, Factor analysis

\begin{abstract}
According to public governance theory, the paper chooses political tolerance, social security, economic management, social justice, public affairs as five aspects through factor analysis, total of 13 indexes, shaping a structured, operational and scientific government public management index system, and based on the evaluation the index system and Shapley Choquet integral, the paper estimates the public governance index of 30 provincial capitals and sorts them. By using the concept and calculation method of the government's public governance index, the government can strengthen the government's public service capacity and provide some suggestions and a certain reference value for government reform.
\end{abstract}

\section{INTRODUCTION}

At present, China is still facing the contradiction between the rapid growth of public demand and insufficient supply of public services. Enhancing people's sense of access and promoting public management reform are not only important starting point to improve the level of government services, but also the implementation of the " innovation, coordination, green development, opening up, and sharing" development concept. Therefore, no matter from the theoretical level or in the practical level, the significance of public governance research is beyond doubt. However, current research on the evaluation of public governance in our country is basically at the conceptual level, so far there is no generally accepted definition so that the degree of public governance is difficult to quantify. In view of this, this paper attempts to establish a public governance index, in order to provide a development scale for government departments, especially local governments. On one hand the paper provides a universal index system for the evaluation of public governance theoretically, on the other hand, the establishment of calculation model of interaction indexes based on the model is completed, and the applicability and superiority is verified by an example.

\section{PUBLIC GOVERNANCE EVALUATION INDEX SYSTEM}

For the government's public governance evaluation index system, the way of list one by one can fully evaluate the government efficiency evaluation, but its cost is too high and practical operability is poor. For the reason, this paper follows the following principles in the design of the index system: the principle of function, the principle of classification and evaluation, the principle of value orientation, the principle of focus, the principle of system, the principle of maneuverability [1].

\subsection{The Design Ideas of Index System}

In the past, most of the evaluation of government effectiveness is focused on the collection of subjective indicators, based on the inherent assumption that the government's good investment is bound to a higher public evaluation. In the actual evaluation, due to bounded ability of the public evaluation and the specific limitations of the research itself, such as the impact of multiple factors, the fuzziness and uncertainty of data from subjective evaluation is difficult to avoid. Based on this, the government's public governance evaluation index of this paper will be a reasonable balance between the subjective and objective indicators index, making objective index oriented towards data and ameliorating satisfaction survey [2]. 


\subsection{Establishment of Index System}

Through the interpretation of the connotation of public governance, this paper determines the government's public governance evaluation system that consists of 13 indexes, they are government barriers $\left(\mathrm{x}_{1}\right)$, government administrative cost $\left(\mathrm{x}_{2}\right)$, the ratio of Non-revenue receipt $\left(\mathrm{x}_{3}\right)$, the proportion of financial investment $\left(\mathrm{x}_{4}\right)$, the proportion of state-owned and private economy $\left(\mathrm{x}_{5}\right)$, number of administrative examination and approval $\left(\mathrm{x}_{6}\right)$, number of $\mathrm{NGO}\left(\mathrm{x}_{7}\right)$, personal safety protection $\left(\mathrm{x}_{8}\right)$, government transparency $\left(\mathrm{x}_{9}\right)$, probity of government $\left(\mathrm{x}_{10}\right)$, public service level $\left(\mathrm{x}_{11}\right)$, social justice $\left(\mathrm{x}_{12}\right)$, and social trust $\left(\mathrm{x}_{13}\right)$,according to the construction principle and design idea of public governance index system of government, referring to the evaluation index from "China provincial capital city public governance report (2015 Edition)".

We use the factor analysis method to reduce the dimension, and the original variables are replaced by a small number of comprehensive indexes (principal factors). After processing the data of 30 cities with SPSS 19.0, we select 5 main factors. The 5 main factors can reflect the information of the original index of $87.282 \%$. The first main factor is mainly related to government barriers, the proportion of state-owned private economy, and the number of NGO, positively related to the government's political inclusion; the second main factors are mainly related to personal safety protection, government integrity, public service level, social trust, mainly reflecting the government's social security level; the third main factors are mainly related to the government's administrative costs, the proportion of non tax revenue, the proportion of fiscal investment, which reflects the government's economic management ability; the fourth main factors are positively correlated with social justice; the fifth main factors are mainly related to the number of administrative examination and approval, government transparency, reflecting the government's openness

Therefore, the government's public governance can be divided into five dimensions: political inclusion, social security, economic management, social justice and public affairs, while the three level index is composed of the above 13 variables. In determining the index weight, we mainly consider the following aspects: use the 5 main factors extracted by factor analysis method as the second level indicators, and the weight is determined by the contribution rate of the principal factor; the weight of the third level is determined by factor score that is process by normalization.

\section{GOVERNMENT PUBLIC GOVERNANCE INDEX CALCULATION MODEL CONSTRUCTION}

On the basis of the evaluation framework of public governance, we can construct the government public governance index used to evaluate all levels of government. Given the correlation between the indicators or interaction, the article uses the Martin system and Shapley Choquet integral operator to measure the public governance index.

\subsection{Calculate the Importance of Indicators by Using the Martin System}

MTS is a pattern recognition technology, and one of its important functions is to measure the importance of attribute set, the following is a brief introduction to use of the MTS:

Set $X=\left\{x_{i} \mid i=1,2, \cdots, n\right\}$ is the attribute set of classification, $P(X)$ is the power set of $X, A \in P(X)$, $|A| \geq 2, Q=\left\{y_{k} \mid k=1,2, \cdots, m\right\}$ and $Q^{\prime}=\left\{y_{k}^{\prime} \mid k=1,2, \cdots, p\right\}$ are two types of samples with obvious differences, and they constitute the sample matrix $Y=\left[y_{k}\left(x_{i}\right)\right]_{m \times n}$ 和 $Y=\left[y_{k}^{\prime}\left(x_{i}\right)\right]_{p \times n}$.

Step 1 Determine the Reference Space

(1) the average and standard deviation of the attributes are obtained from the sample data Y.

$$
\begin{gathered}
\mu\left(x_{i}\right)=\frac{1}{m} \sum_{k=1}^{m} y_{k}\left(x_{i}\right) \\
s\left(x_{i}\right)=\sqrt{\frac{1}{m-1} \sum_{k=1}^{m}\left[y_{k}\left(x_{i}\right)-\mu\left(x_{i}\right)\right]^{2}}
\end{gathered}
$$

(2) use $\mu\left(x_{i}\right)$ and $s\left(x_{i}\right)$ to standardize the matrix Y to obtain the standardized sample 
matrix $Z=\left[z_{k}\left(x_{i}\right)\right]_{m \times n}$.

$$
z_{k}\left(x_{i}\right)=\frac{y_{k}\left(x_{i}\right)-\mu\left(x_{i}\right)}{s\left(x_{i}\right)}, \mathrm{k}=1,2, \cdots, m, i=1,2, \cdots, n
$$

(3) calculate the correlation coefficient between attributes

$$
R_{A}=\frac{1}{m-1} \sum_{k=1}^{m}\left(Z_{A}^{(k)}\right)^{T} Z_{A}^{(k)}, A \in P(X),|A| \geq 2
$$

thereinto $Z_{A}^{(k)}$ represents the property set A under the kth sample data.

Step 2 Calculate the Mahalanobis Distance of Each Sample

(1) use $\mu\left(x_{i}\right), s\left(x_{i}\right)$ comes from formula (1) to standardize

$$
v_{k}\left(x_{i}\right)=\frac{y_{k}^{\prime}\left(x_{i}\right)-\mu\left(x_{i}\right)}{s\left(x_{i}\right)}, k=1,2, \cdots, p, i=1,2, \cdots, n
$$

(2) the Mahalanobis distance of each sample is calculated, according to the attribute set A

$$
d_{A}^{(k)}=\frac{1}{n} v_{A}^{(k)} R_{A}^{-1}\left(v_{A}^{(k)}\right)^{T}, k=1,2, \cdots, p
$$

Step 3 calculate the importance of attribute set $\mathrm{A}$ in the classification process

$$
\eta_{A}=-10 \log _{10}\left[\frac{1}{p} \sum_{k=1}^{p} \frac{1}{d_{A}^{(k)}}\right]
$$

thereinto the greater the degree is ,more important attribute set $\mathrm{A}$ is.

In order to ensure the importance of attribute $A$ is not less than the importance of the use of all attributes in A and, by the idea of the literature [3], the importance of the property can be used as follows.

$$
\left\{\begin{array}{c}
\max \varepsilon_{1}+\varepsilon_{2}+\cdots+\varepsilon_{2^{n}-n-1} \\
\text { s.t. } \eta_{A}-\sum_{i \in A} \geq \varepsilon_{p}, p=1,2, \cdots,\left(2^{n}-n-n\right) \\
-1 \leq \varepsilon_{p} \leq 1, p=1,2, \cdots,\left(2^{n}-n-n\right) \\
0 \leq \eta_{i} \leq 1, \sum_{i=1}^{n} \eta_{i}=1, i=1,2, \cdots, n
\end{array}\right.
$$

\subsection{Calculate the Shapley Value of a Single Attribute}

$w_{i}$ reflects the relative importance of individual attributes, and B reflects the global importance, Shapley property of $x_{i}$ can merge the two together. According to the Ref.3, there is a certain proportional relationship between fuzzy measure and weight, that is $\mu\left(x_{i}\right) / \mu\left(x_{j}\right)=w_{i} / w_{j}$, so we can use $\mu\left(x_{i}\right)$ to replace the weight, the Shapley value of the attribute $x_{i}$ is calculated as:

$$
I_{i}=w_{i} \eta_{i} / \sum_{k=1}^{n} w_{k} \eta_{k}, i=1,2, \cdots, n
$$

\subsection{Use Choquet Integral to Calculate the Comprehensive Attribute Value}

As a nonlinear integral operator, Choquet integral can be used to deal with multiple attribute decision making problems with interaction between targets. Set a is Shapley value defined on the $\mathrm{X}$ and $\mathrm{B}$ is interactive index value defined on the $\mathrm{X}$, the Choquet integral of function $\mathrm{f}$ on $I_{i}$ and $I_{i j}$ can be expressed as

$$
C_{\mu}(f)=\sum_{i=1}^{n} I_{i} f\left(x_{i}\right)-\frac{1}{2} \sum_{\left.\left\{x_{x}, j \in \in\right\}\right\}} I_{i j}\left|f\left(x_{i}\right)-f\left(x_{j}\right)\right|
$$

thereinto $I_{i j}$ is the interactive value of attribute $\mathrm{i}$ and attribute $\mathrm{j}$, we set up a multi-objective optimization model to solve the problem according to Ref.3,as shown.

$$
\left\{\begin{array}{c}
\max \left(C_{\mu}\left(f_{1}\right), C_{\mu}\left(f_{2}\right), \cdots, C_{\mu}\left(f_{m}\right)\right) \\
\text { s.t. }-2 I_{i} \leq \sum_{j \in T^{\imath}\left(x_{j}\right\}} I_{i j}-\sum_{j \in T} I_{i j} \leq 2 I_{i}, i=1,2, \cdots, n \\
-1 \leq I_{i j} \leq 1,\left\{X_{i}, X_{j}\right\} \subset X
\end{array}\right.
$$

\subsection{Evaluation Steps for Government Public Governance Index}

I First of all, we set $w_{i}$ as the relative importance of the secondary index on the upper level index;

II Calculate the importance of attribute set A by MTS; 
III Calculate the importance of a single attribute;

IV Obtain the Shapley value of a single attribute;

$\mathrm{V}$ Computer the interaction value between indexes;

VI Use Choquet to obtain the comprehensive value of the superior index;

VII Repeat the above steps and get the final sample of public governance index.

\section{EMPIRICAL STUDY}

We select 30 provincial capitals (excluding Lhasa) as samples and calculate the government public governance index based on the above steps, data is from China's provincial capital city public governance report (2015 Edition). The results of the measurement are generally similar to the results reported in the original report, however, the specific value has a slight change, as shown in figure 1 . The reason is that the measurement model use the Shapley value to calculate the Choquet index instead of weight index, so it reduces the interaction between indexes, and the original report is simply the sum of weighted index, not considering the relationship between the function index. From the horizontal comparison, Beijing, Shanghai, Guangzhou, Hangzhou and other economically developed city are in the top row, central-section city and western capital mainly are in later position, suggesting that the relevant between government public governance level and the level of economic development positively. From the data point of view, the gap between the first and the last one in the government public governance index is large, indicating that the government has a lot of work to do in the co-ordination of regional public governance.

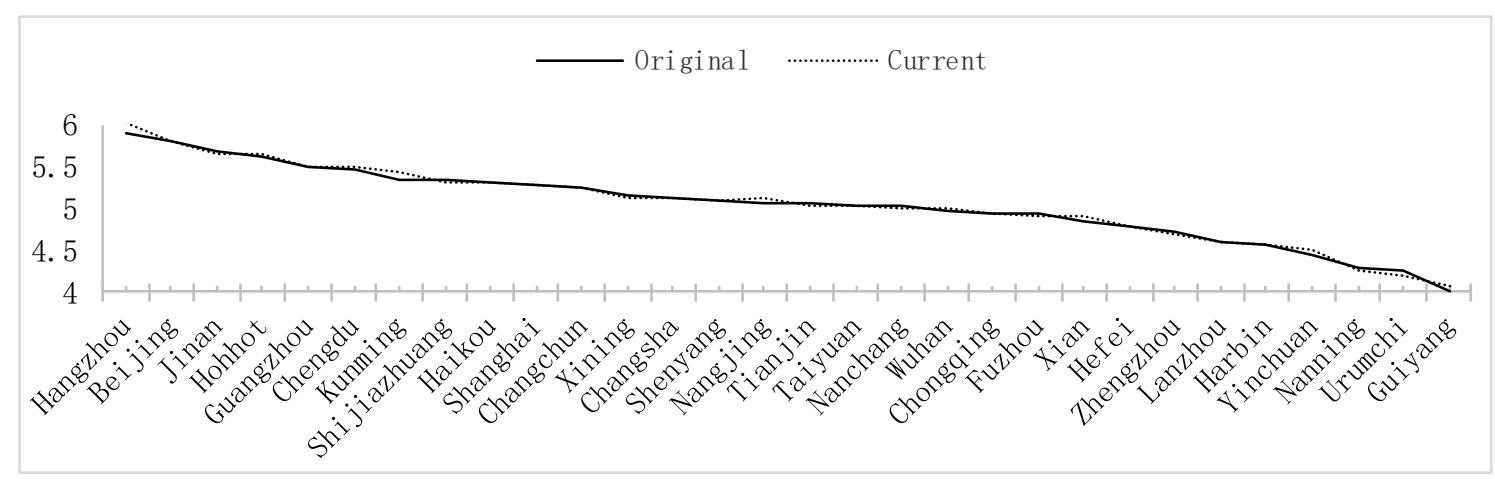

FIGURE 1 Provincial capital city public governance index change chart

\section{CONCLUSION}

Based on the analysis of the connotation of public governance, the paper try to establish a government public governance evaluation system from five dimensions ,the political tolerance, social security, economic management, social justice and public affairs, by using factor analysis method. And we construct measurement model based on Shapley Choquet integral, and the applicability and superiority of the model are verified by 30 provincial capitals, having certain theoretical and practical significance to guide the construction of government public governance capacity.

Because of the relatively few studies on the evaluation of public governance, there is no authoritative evaluation system now, the study on the government's public governance is just initial exploration, some problems are hard to avoid, such as blur boundaries of public governance and inaccuracy of public evaluation, the selection of indicators, the weight of the index and the model need to be further studied.

\section{REFERENCE}

[1] Wang Tianqi, Huang Ying. Construction and Application of the Index System of Cultural 
Strength Measurement and Its Application [J]. Statistics and Decision Making, 2015, (5):19-23.

[2] Zhou Zhi Yi. A Reasonable Balance Between Subjective and Objective Indicators in Government Performance Evaluation [J]. Administrative Forum, 2015, (3):37-44.

[3] Chang Zhipeng, Cheng Longsheng, Liu Jiashu. Multi-Attribute Decision Making Method Based on Mahalanobis-Taguchi System and 2-additive Choquet integral [J]. Journal of Engineering Management, 2016, (1)133-139. 